Márcio Soares Élie Azoulay

\title{
Critical care management of lung cancer patients to prolong life without prolonging dying
}

Received: 18 August 2009

Accepted: 18 August 2009

Published online: 19 September 2009

(C) Copyright jointly hold by Springer and ESICM 2009

This editorial refers to the article available at:

doi:10.1007/s00134-009-1625-y.

\section{Soares (®)}

Intensive Care Unit, Instituto Nacional de Câncer,

Centro de Tratamento Intensivo, Pça. Cruz Vermelha,

23, $10^{\circ}$ Andar, Rio de Janeiro, RJ 20230-130, Brazil

e-mail: marciosoaresms@yahoo.com.br

Tel.: +55-21-25066120

Fax: $+55-21-22948620$

É. Azoulay

Service de Reanimation Medicale,

Hopital Saint-Louis et Universite Paris 7,

Assistance Publique Hôpitaux de Paris,

Paris, France

Over the last few decades, numerous studies showing improved short-term survival rates in critically ill patients with solid tumors or hematological malignancies have put an end to the long-accepted practice of routinely refusing admission of cancer patients to the intensive care unit (ICU) [1-3]. Survival gains were demonstrated in patients with a variety of characteristics including neutropenia [4], severe sepsis [5, 6], acute kidney injury [7], prolonged ICU admission [8] and recent chemotherapy [9], as well as in specific subgroups of patients believed to have very low chances of survival, such as patients with lung cancer $[10,11]$. These studies highlighted not only the beneficial impact of advances in critical care and in hematology and oncology, but also the inadequacy of our triage criteria [12]. Furthermore, they have established that a crucial goal is the early management (and even prevention) of organ dysfunction [13, 14].
The decision to admit a patient with cancer to the ICU is multifaceted. Close collaboration among the intensivists and the hematologists and oncologists is essential, as several specific aspects must be discussed in detail. Of note, most of the patients referred to the ICU have active disease, which is usually newly diagnosed, suggesting preliminary triage by the oncologists and hematologists before ICU referral. Furthermore, the main reasons for ICU admission are severe acute complications related to the cancer treatments or cancer itself, indicating that patients with severe co-morbidities are considered poor candidates for ICU admission. It should be borne in mind that the ICU experience generates its own physical, functional and emotional burdens $[15,16]$. In a study of non-cancer ARDS patients, survivors lost $18 \%$ of their baseline body weight during the ICU stay, experienced severe muscle weakness and fatigue, and had persistent functional disability 1 year after ICU discharge [16]. These findings are extremely relevant, as treatment decisions are substantially influenced by the clinical condition of the patient. In ICU cancer patients, poor performance status has been associated with mortality [7, 17]. Moreover, poor performance status may prevent the use of optimally aggressive chemo- and radiation therapy regimens and/or decrease the ability to achieve radical surgical resection, thereby diminishing long-term survival. In these patients subjected to multiple levels of triage, unrestricted ICU admission with full-code management has been recommended to avoid inappropriate treatment limitation related to inadequate triage decisions [1]. However, no data were available about the impact of ICU admission and management strategies on long-term survival, disease-free survival and quality of life.

In the current issue of Intensive Care Medicine, Dr. Roques and colleagues report the outcomes of 104 patients with lung cancer requiring ICU management because of medical complications [18]. In this valuable contribution to the existing literature, the encouraging 
Table 1 The ASSESS approach: a five-step framework for a routine comprehensive evaluation in studies of ICU patients with cancer

\begin{tabular}{|c|c|}
\hline Domain & Description and rationale \\
\hline Triage for ICU Admission & $\begin{array}{l}\text { Triage criteria for ICU admission used by oncologists/hematologists and intensivists. Detailed evaluation } \\
\text { of the ICU-admission process, including data on non-ICU cancer patients with various levels of organ } \\
\text { dysfunction on the wards and data on the effects of early ICU admission }\end{array}$ \\
\hline Code Status & $\begin{array}{l}\text { Code status to be implemented at ICU admission: full code, ICU trial for a short period ( } 3-5 \text { days with } \\
\text { full-code status then re-evaluation) or early implementation of palliative care }\end{array}$ \\
\hline $\begin{array}{l}\text { ICU Support and patient's } \\
\text { Evolution }\end{array}$ & $\begin{array}{l}\text { ICU management, with a reappraisal of the intensity, duration and nature of life-supporting treatments } \\
\text { provided in the ICU. Evaluation of incidence, nature and outcome of organ failures and residual organ } \\
\text { dysfunction }\end{array}$ \\
\hline Survival & Go beyond short- and medium-term survival by evaluating long-term outcomes (up to 1 year) \\
\hline Picture of Survivors & $\begin{array}{l}\text { Description of ICU survivors including qualitative evaluation of the ability to undergo chemotherapy, } \\
\text { disease-free survival, functional status, health-related quality of life and post-ICU burden (stress-related } \\
\text { disorders, anxiety and depression) }\end{array}$ \\
\hline
\end{tabular}

short- and medium-term survival rates corroborate the results of other recent studies $[10,11]$. One of the most interesting aspects of the study by Dr. Roques et al. [18] is the 6-month evaluation of ICU survivors. Survival after 6 months was $40 \%$, and, interestingly, $68 \%$ of patients had received specific anticancer treatments after hospital discharge. Another major finding from this study is the significantly higher survival rate in patients given anticancer treatments (79\%) compared to the other patients $(21 \%)$. As expected, disease progression was the main determinant of death in this last patient subgroup.

The study patients were clearly selected for ICU admission, as only a minority of them had airway obstruction $(10 \%)$ or cancer progression $(21 \%)$. We strongly support these selection criteria $[1,10]$. Moreover, Dr. Roques and co-workers were clearly aware of the recent evidence indicating improved survival in critically ill cancer patients, as they provided aggressive life support, with $53 \%$ of patients receiving ventilatory support and $41 \%$ vasoactive agents.

Dr. Roques et al. provide valuable information on ICU survivors, about which little was known until now [7, 15]. There is an urgent need for studying an array of outcomes that extends beyond ICU or hospital survival. The effects of the critical illness and its treatments on multiple domains must be evaluated in ICU survivors. In addition, the goal of ICU management is not merely to ensure survival, but, instead, to ensure survival with a health status that allows anticancer treatment. The present study makes a valuable contribution to the existing literature by establishing that intensivists are sharply focused on longterm survival. Most of the ICU survivors received anticancer treatments; the others probably received only palliative care and had a high short-term mortality rate. An earlier study found that previous chemotherapy did not adversely affect patient outcomes [9]. Moreover, starting chemotherapy in the ICU, principally in patients with high-grade malignancies, was beneficial, even in patients who had specific cancer-related organ dysfunctions or infections [19]. Nevertheless, there is no evidence to date that these benefits extend to lung-cancer patients, even those with small-cell lung carcinoma (SCLC). Although a fast response would be expected, chemotherapy in the ICU failed to improve outcomes [10], particularly in SCLC patients with extensive disease [20]. Despite the introduction of new treatment strategies, acute respiratory failure secondary to pulmonary involvement or airway obstruction by the malignancy remains associated with very high mortality rates $[10,17,20]$.

We advocate the use, whenever possible, of a systematic comprehensive approach in future studies of cancer patients admitted to the ICU. This approach includes five steps that can be summarized by the acronym ASSESS (Table 1): (1) triage criteria for ICU Admission by oncologists/hematologists and ICU physicians; (2) code Status implemented at ICU admission (full code, ICU trial or early treatment limitation); (3) ICU Support; and patient's Evolution; (4) short- and long-term Survival; (5) appropriate description of ICU Survivors. First, we need detailed evaluations of the ICU admission process, including data on non-ICU cancer patients with various levels of organ dysfunction who are managed on the wards. A formal evaluation of early ICU admission of cancer patients is in order. Second, we must convince our colleagues that many patients are eligible for ICU admission with a trial of full-code treatment for at least 35 days followed by a re-evaluation of the treatment strategy $[1,3]$. Furthermore, the provision of palliative care (e.g., noninvasive ventilation) in the ICU should be carefully evaluated. Third, the ICU management strategy needs reappraisal. For instance, the lower mortality in cancer patients receiving mechanical ventilation warrants a change in policies about withholding intubation or prolonging noninvasive ventilation in hypoxemic patients [21]. Moreover, studies on the incidence, nature and outcome of organ failures and residual organ dysfunction are necessary. Fourth, in addition to ICU and hospital survival, long-term outcomes (up to 1 year) must be routinely assessed. Finally, in ICU survivors, we must evaluate qualitative indicators such as the ability to undergo chemotherapy, disease-free survival, functional status, quality of life and post-ICU burden (e.g., stress- 
related disorders, anxiety and depression). The findings from the study by Dr. Roques and colleagues show that the main goal of ICU management of cancer patients is to improve long-term survival. In non-admitted patients and in patients whose post-ICU health status precludes anticancer therapy, palliative care seeks to achieve the valuable goal of improving the quality of the dying process.
Acknowledgments Dr. Soares received a research grant from the Brazilian public research funding agency CNPq.

Conflict of interest statement None.

\section{References}

1. Darmon M, Azoulay E (2009) Critical care management of cancer patients: cause for optimism and need for objectivity. Curr Opin Oncol 21:318326

2. Pène F, Soares M (2008) Can we still refuse ICU admission of patients with hematological malignancies? Intensive Care Med 34:790-792

3. Azoulay E, Afessa B (2006) The intensive care support of patients with malignancy: do everything that can be done. Intensive Care Med 32:3-5

4. Darmon M, Azoulay E, Alberti C, Fieux F, Moreau D, Le Gall JR, Schlemmer B (2002) Impact of neutropenia duration on short-term mortality in neutropenic critically ill cancer patients. Intensive Care Med 28:1775-1780

5. Pène F, Percheron S, Lemiale V, Viallon V, Claessens YE, Marqué S, Charpentier J, Angus DC, Cariou A, Chiche JD, Mira JP (2008) Temporal changes in management and outcome of septic shock in patients with malignancies in the intensive care unit. Crit Care Med 36:690-696

6. Larche J, Azoulay E, Fieux F, Mesnard L, Moreau D, Thiery G, Darmon M, Le Gall JR, Schlemmer B (2003) Improved survival of critically ill cancer patients with septic shock. Intensive Care Med 29:1688-1695

7. Soares M, Salluh JI, Carvalho MS, Darmon M, Rocco JR, Spector N (2006) Prognosis of critically ill patients with cancer and acute renal dysfunction. $\mathbf{J}$ Clin Oncol 24:4003-4010

8. Soares M, Salluh JI, Torres VB, Leal JV, Spector N (2008) Short- and longterm outcomes of critically ill patients with cancer and prolonged ICU length of stay. Chest 134:520-526
9. Vandijck DM, Benoit DD, Depuydt PO, Offner FC, Blot SI, Van Tilborgh AK, Nollet J, Steel E, Noens LA,

Decruyenaere JM (2008) Impact of recent intravenous chemotherapy on outcome in severe sepsis and septic shock patients with hematological malignancies. Intensive Care Med 34:847-855

10. Soares M, Darmon M, Salluh JI, Ferreira CG, Thiéry G, Schlemmer B, Spector N, Azoulay E (2007) Prognosis of lung cancer patients with lifethreatening complications. Chest 131:840-846

11. Adam AK, Soubani AO (2008) Outcome and prognostic factors of lung cancer patients admitted to the medical intensive care unit. Eur Respir J 31:47-53

12. Thiéry G, Azoulay E, Darmon M, Ciroldi M, De Miranda S, Lévy V, Fieux F, Moreau D, Le Gall JR, Schlemmer B (2005) Outcome of cancer patients considered for intensive care unit admission: a hospital-wide prospective study. J Clin Oncol 23:4406-4413

13. Peigne V, Rusinová K, Karlin L, Darmon M, Fermand JP, Schlemmer B, Azoulay E (2009) Continued survival gains in recent years among critically ill myeloma patients. Intensive Care Med 35:512-518

14. Khassawneh BY, White P Jr, Anaissie EJ, Barlogie B, Hiller FC (2002) Outcome from mechanical ventilation after autologous peripheral blood stem cell transplantation. Chest 121:185-188

15. Nelson JE, Meier DE, Oei EJ, Nierman DM, Senzel RS, Manfredi PL, Davis SM, Morrison RS (2001) Self-reported symptom experience of critically ill cancer patients receiving intensive care. Crit Care Med 29:277-282
16. Herridge MS, Cheung AM, Tansey CM, Matte-Martyn A, Diaz-Granados N, AlSaidi F, Cooper AB, Guest CB, Mazer CD, Mehta S, Stewart TE, Barr A, Cook D, Slutsky AS, Canadian Critical Care Trials Group (2003) One-year outcomes in survivors of the acute respiratory distress syndrome. N Engl J Med 348:683-693

17. Soares M, Salluh JI, Spector N, Rocco JR (2005) Characteristics and outcomes of cancer patients requiring mechanical ventilatory support for $>24 \mathrm{hrs}$. Crit Care Med 33:520-526

18. Roques S, Parrot A, Lavole A, Ancel P-Y, Gounant V, Djibre M, Fartoukh M (2009) Six-month prognosis of patients with lung cancer admitted to the intensive care unit. Intensive Care Med. doi:10.1007/s00134-009-1625-y

19. Darmon M, Thiery G, Ciroldi M, de Miranda S, Galicier L, Raffoux E, Le Gall JR, Schlemmer B, Azoulay E (2005) Intensive care in patients with newly diagnosed malignancies and a need for cancer chemotherapy. Crit Care Med 33:2488-2493

20. Jennens RR, Rosenthal MA, Mitchell P, Presneill JJ (2002) Outcome of patients admitted to the intensive care unit with newly diagnosed small cell lung cancer. Lung Cancer 38:291-296

21. Soares M, Salluh JI, Azoulay E (2009) Noninvasive ventilation in patients with malignancies and hypoxemic acute respiratory failure: a still pending question. J Crit Care. doi: 10.1016/j.jcrc.2009.04.001 